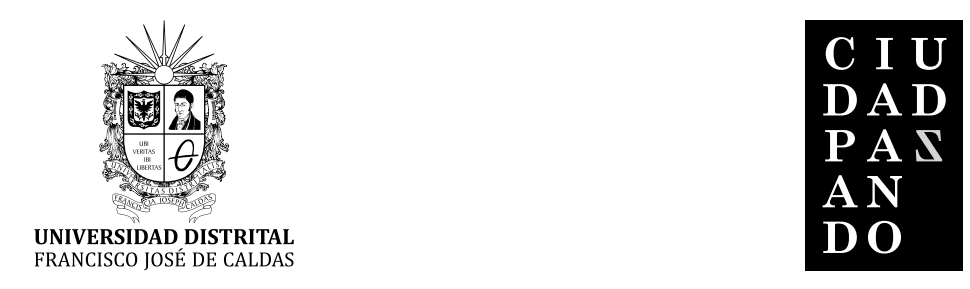

RESEÑA

\title{
Narrativas testimoniales: poéticas de la alteridad ${ }^{1}$
}

\section{Sebastián Gauta ${ }^{2}$}

Para citar: Gauta, S. (2018). Narrativas testimoniales: poéticas de la alteridad. Revista Ciudad Paz-ando, 11(1), pp. 83-86. doi: https://doi.org/10.14483/2422278X.12216

Fecha de recepción: 16 de junio de 2017

Fecha de aprobación: 31 de octubre de 2017

La historia no es algo que ya pasó y, sobre todo, que ya les pasó a hombres notables y célebres. Es mucho más. Es lo que le sucede al pueblo común y corriente todos los dias, desde que se levanta lleno de ilusiones hasta que cae rendido en la noche sin esperanzas. No se necesitan documentos acartonados y descoloridos por el tiempo para convertir un hecho en histórico; la historia no se refugia en las notarías ni en los juzgados, ni siquiera en los periódicos. La historia es una voz llena de timbres y de acentos de gente anónima

Molano Del Llano, 119

En este sentido, Narrativas testimoniales: poéticas de la alteridad es una escritura colectiva en donde convergen las reflexiones, experiencias, sentires y propuestas educativas de las maestras e investigadoras Jeritza Merchán, Clara Castro, Lorena Garzón y Piedad Ortega, mujeres que le han apostado a la construcción de una escuela crítica, humana y militante de la vida, la memoria y la transformación de las prácticas y los discursos hegemónicos y retardatarios.; es por ello que el presente libro es una invitación a caminar juntos y construir utopías en la transición política que se puede vislumbrar en el horizonte del posacuerdo, pactado entre la guerrilla de las Farc-Ep y el Gobierno Nacional.

En Colombia los ciclos de violencia política han sido permanentes y se han configurado por más de 70 años (periodización que varía según el autor que se tome como referencia), el resultado de dicho período de violencia es la ruptura del tejido social, el aniquilamiento y la estigmatización del pensamiento disidente. Ante el vacío, las ausencias y la imposición del miedo y el silenciamiento que han dejado la guerra en Colombia, las autoras ofrecen la pedagogía de la memoria, la cual busca sanar las heridas, recomponer el vínculo y volver al nos-otros.
En esa medida, Narrativas testimoniales: poéticas de la alteridad es una propuesta compuesta por cuatro capítulos o ventanas para vislumbrar en el horizonte los sueños, las esperanzas, las memorias y los sentires reprimidos por el rigor de la guerra, la cual desde siempre arrebató y arrebata la vida de hombres y mujeres en nombre de la "seguridad democrática", la "seguridad nacional" y el "combate contra el enemigo interno".

\section{Primera ventana: "La didáctica, una puesta en escena reflexiva"}

En este aparte las autoras establecen que:

... la didáctica es una apuesta en escena reflexiva y sensible sobre la forma como desarrollamos los procesos pedagógicos y como logramos participar con Otros en su construcción teórica y práctica, no solo en el campo de la palabra, sino también en el de la acción y el acontecimiento, como fuentes de experiencias compartidas. Es un diálogo de saberes y discursos, cuerpos, gestos, duelos y traumas, también de potencialidades y discursos que nos posibilitan la construcción individual y colectiva de narrativa, en los cuales participan quienes quieren y pueden

1 Merchán, J; Ortega, P; Castro, C; Garzón, L. (2016). Narrativas testimoniales: poéticas de la alteridad. Bogotá: Universidad Pedagógica Nacional.

2 Licenciado en Ciencias Sociales de la Universidad Pedagógica Nacional. Correo electrónico: gauta72@gmail.com 
aportar algo de lo que sienten, viven y desean (Merchán et al., 2016, p. 28).

Con lo cual se evidencia de manera concreta el compromiso ético-político de los maestros, estudiantes y demás actores del acto educativo en sí. Ético en el sentido de escuchar, comprender, dialogar y estar pendiente del otro, pero no desde una perspectiva paternalista o asistencialista, sino de manera solidaria, fraterna y en la búsqueda incesante de amor eficaz. Política en cuanto asume la realidad del educando, o del otro, en un horizonte de trabajo colectivo en pro de justicia, equidad y dignidad como seres humanos que sienten, piensan y reflexionan.

Dichos aspectos éticos y políticos son anclados con la pedagogía critica como práctica reflexiva, entorno a los modos de constitución de sujetos colectivos donde la acción pedagógica se asume como una relación de alteridad, basada en la responsabilidad, la hospitalidad y las múltiples construcciones poéticas para significar y resignificar al otro, donde las narrativas testimoniales de las víctimas y sobrevivientes de la violencia política “... se convierten en una apuesta metodológica de carácter hermenéutico, vinculado con la pedagogía de la memoria y su relacionamiento con la memoria individual y los marcos sociales de la memoria" (Merchán et al., 2016, p. 34).

En esa medida, es importante el posicionamiento teórico que las autoras asumen desde Paul Ricoeur entorno a la memoria como una pregunta por el devenir, por lo que transcurre callado y silenciado, en particular en contextos de violación de derechos fundamentales como la existencia, la implantación del terror y la desconfianza. Asimismo, "Es una memoria que recupera el rostro y la corporeidad, sus nichos vinculares, sus construcciones, sus construcciones narrativas desde la experiencia del dolor, del desarraigo y de la desprotección. Es una memoria de indagación y también de esperanza" (2017, p. 35).

El proceso de elaboración de las memorias desde una perspectiva terapéutica se plantea a partir de dos instancias: la primera "poder decir", lo cual implica devolverles la voz a los hombres y mujeres que han atravesado hechos victimizantes, dar participación activa en la construcción de políticas de la memoria y en la reparación integral de los derechos resquebrajados; la segunda, "poder contar y poder contarse", significa construir una identidad subjetiva y propia a partir de la experiencia, el dolor y los sentires vividos por el sobreviviente.

Frente al diseño metodológico propuesto por las autoras, la gramática teleológica le imprime un conjunto de sentidos y dimensiones tanto de carácter epistemológico como estético, ético y político, donde son puestas en diálogo técnicas y métodos de investigación, así como las relaciones pedagógicas con el saber, el pensamiento, el poder, los territorios, las trayectorias vivenciales y la experiencia. En síntesis, el apartado metodológico consiste en poner en diálogo permanente la experiencia, la teoría y la práctica pedagógica, elementos que permiten la producción de saberes para la acción y la transformación de la cultura política como búsqueda incesante.

Se tiene como punto de encuentro las narrativas testimoniales, entendidas estas como "presencia-ausencia" donde convergen silencios, miedos, dolores, pero en particular la experiencia de cada sujeto. Se convierte en una potencia pedagógica, en cuanto tiene la posibilidad de controvertir la historia oficial, la cual se ha encargado de homogenizar e imponer grandes relatos de nombres y sucesos sin contextos, atentando así con la subjetividad.

En síntesis, esta primera ventana busca poner en discusión la didáctica crítica y las narrativas testimoniales en un plano educativo con sentido ético-político, donde la alteridad es el eje central para la restitución de la condición humana tras décadas de violencia política.

\section{Segunda ventana: "Didáctica de la pedagogía de la memoria, un encuentro con la palabra"}

Las investigadoras plantean la discusión en torno al rol de la escuela y los diferentes escenarios educativos, además de la importancia de la narrativa testimonial como un vehículo movilizador y formador, capaz de crear, activar y recuperar las memorias subalternas. En esa medida, son señaladas las tensiones vividas desde el quehacer pedagógico producto de las políticas institucionales, las cuales han pretendido formar sujetos obedientes, productivos y temerosos a la ley en el marco de ciudanías "patrióticas", "cívicas", "democráticas" o "competentes".

Además de ello, en los territorios del país dominados por los diferentes actores armados han sido impuestas "costumbres" que agreden hábitos culturales y rompen con las cosmogonías propias de las comunidades, enmarcando el accionar y los sentido de los sujetos en el "deber ser, actuar y pensar" determinado de manera arbitraria por el actor armado; de no cumplirse con dicha muerte hermenéutica, representada en eliminar discursos, identidades, racionalidades y formas diferentes de entender y comprender el mundo, era procedido el exterminio físico.

Por ello, se convierte en un imperativo pedagógico pensar en didácticas de la memoria para desarrollar procesos reestructurantes de las formas de enseñanza de la historia del conflicto social y armado, la resolución de conflictos, la diferencia y la alteridad, lo cual se materializa en el quehacer pedagógico atreves de dos consignas ¡Nunca Más!, ¡Basta Ya! Nunca más, el exterminio del opositor, nunca más las armas para la tramitación del conflicto y la diferencia, nunca más el señalamiento y la estigmatización. Basta ya la indiferencia, basta ya el silenciamiento cómplice.

Dichas didácticas de las memorias implican cambios en las prácticas y los discursos educativos, en educar memoriosamente para comprender y para que no se vuelva a repetir la violencia política; asimismo, las autoras señalan: 
aludimos a las didácticas para el no olvido desde la poética de la alteridad, es decir, desde la reflexión estética, política y ética del dolor y el sufrimiento producidos por la guerra, la violencia política y el conflicto armado interno, con el ánimo de potenciar los principios de alteridad frente a esos Otros con quienes no podemos seguir siendo indiferentes. Ya que hacen parte, en los ámbitos íntimos, privados y públicos, de nuestra propia constitución como seres humanos [...] de un país que hoy le apuesta a la tramitación del conflicto armado desde lo político (Merchán et al., 2016, p. 72).

Solo el estudio de la historia reciente, el uso pedagógico de las memorias del dolor, posibilita la formación de ciudadanías activas, participativas, críticas y acordes a los retos de la cultura política del momento histórico, donde la indiferencia y el "importaculismo" no haga parte del código moral y de conducta de los colombianos.

\section{Tercera ventana: "Narrativas memoriales: relatos latinoamericanos"}

Se presenta un panorama del tratamiento que han tenido las memorias en el subcontinente durante y después de los regímenes dictatoriales a mediados del siglo pasado, presentando así las tensiones entre el estudio de la historia reciente y del testimonio como sinónimo de resistencia y el silenciamiento como sentido de deshumanización.

En cuanto a las políticas de la memoria desarrolladas en los periodos de transición de los regímenes dictatoriales a la democracia, estas se han caracterizado por ser cautelosas en el escenario gubernamental. Respecto a la escuela y el quehacer pedagógico, los educadores se han visto temerosos a asumir ciertas temáticas del pasado reciente de sus respectivos países, recordando también la manipulación que tuvieron la enseñanza de las ciencias sociales durante dichos periodos de violencia política, donde predominaban las versiones hegemónicas y homogéneas, legitimadoras de la deshumanización, la muerte y el silenciamiento.

Por su parte, quienes han tomado la iniciativa y alzado la voz de denuncia han sido las organizaciones comunitarias, movimientos sociales, las víctimas y los sobrevivientes a los sucesos del terror, las polifonías han sido puestas al servicio de la verdad histórica y la justicia en los escenarios públicos y de participación. Asimismo, los cambios generacionales son las potencias para transmitir los testimonios constituidos por la experiencia vivida de una generación determinada hacia los jóvenes, estableciendo un diálogo permanente del pasado con el ahora, de los sobrevivientes con las nuevas generaciones.

Esto supone el desafío de construir una pedagogía de la memoria que, a partir de las narrativas como opción didáctica, sea capaz de enfrentarse a la alteridad vehicula- da a través de los relatos, los soportes de la palabra y las narrativas mismas. Estamos ante poéticas de la alteridad puesto que estamos ante posicionamientos y enunciaciones surgidos de experiencias vitales límite y agenciados a través de representaciones, universidad de sentido y formas de expresión estética que pueden resultar distintos a los propios (2017, p. 127).

\section{Cuarta ventana: "Formar para la sumisión o para la dignidad, ¿es esta es la cuestión de la memoria?"}

De manera dialógica, las investigadoras retoman los planteamientos hechos por Mantegazza entorno a la necesidad de trabajar pedagógicamente en la enseñanza de la política y la historia social de los pueblos. Elementos que son asumidos por la pedagogía de la memoria, pues:

... es una puesta por formar para deconstruir la violencia, recuerda para poner de presente la peligrosidad de banalizar el mal y acoge el dolor como categoría para confrontar la estupidez presente en los medios de comunicación desde el sentimiento y la razón o desde la esfera cotidiana de la inmediatez (2016, p. 144).

Asimismo, la rebeldía como concepto ético de resistencia es el punto de partida por humanizar lo humano, por conquistar los derechos de las víctimas y los sobrevivientes a la verdad, la justicia y la construcción de políticas de la memoria reparadoras, las cuales contribuyan a la construcción y consolidación de una ética del cuidado del otro, del enamoramiento; razón por la cual, las autoras hacen el llamado de atención a asumir una "ética de la colaboración" en términos de Alejandro Castillejo, por asumir una actitud respetuosa en los procesos investigativos para dar tratamiento a los testimonios de los sujetos participantes en aras de no generar nuevas revictimizaciones o lucros por parte del investigador.

\section{A manera de síntesis}

Las anteriores ventanas propuestas por las autoras responden en parte a las necesidades históricas de la escuela y la sociedad colombiana, donde el cuidado del otro es una premisa ética y política por reconstruir un país que se encuentra en transición para ampliar la democracia y la resolución de los conflictos desde el argumento y no desde las armas o el aniquilamiento. Es importante reseñar la vitalidad de Narrativas Testimoniales: poéticas de la alteridad como una propuesta pedagógica concreta, madura y acorde a la realidad de los diferentes escenarios de aprendizaje, le apuesta a la construcción de ciudadanías críticas, alternativas y amorosas.

Es imprescindible que este libro recorra el territorio, llegue a la Colombia profunda, a las Zonas Veredales Transitorias de Normalización como una propuesta 
educativa para la guerrillerada, la población civil y los diferentes sectores políticos del país, lo anterior en aras de realizar un gran diálogo nacional.

A Jeritza, Clara, Lorena y Piedad, gratitud por poner en nuestras manos y pensamiento su vitalidad y sus ganas de transformar la sociedad con una pedagogía del cuidado y del entendimiento con el otro, por ampliar el debate intergeneracional donde se ponen en juego las memorias de los sobrevivientes con las nuevas generaciones de jóvenes que se resisten a vivir en guerra.

Para finalizar, el diseño estético del libro cargado de colores y figuras con sus respectivas invitaciones a ver, leer, escribir, escuchar y demás, inspira para hacer de la palabra, la poesía y el arte, la herramienta para transformar la realidad. 